\title{
AL-RIBA (BUNGA) DALAM PERSPEKTIF SEJARAH \& AGAMA
}

\begin{abstract}
Abd. Ghafur*
Abstract: Riba is not a matter of concern in Islamic society, but actually outside of Islam also take seriously problem of usury. For, usury has become a discussion among Jews, Greeks, as well as Romans and Christians.

Riba in the divine religion has been declared haraam, the Jews forbade the taking of flowers. This prohibition is contained in the Old Testament (the Old Testament) as well as the Talmudic laws. In Roman and Greek societies prohibited interest in its territory. Interest at that time was strictly prohibited by strict laws. The Christian side considers that the verse contained in Luke 6: 34-35 as a verse that condemns the practice of making flowers. In the Islamic religion also strictly prohibits the practice of usury. It is contained in the Qur'an and as-Sunna.

Keywords: Riba, History, Religion
\end{abstract}

\section{A. Pendahuluan}

Riba Bukanlah suatu hal yang menjadi persoalan di masyarakat Islam saja, tetapi sebenarnya berbagai kalangan di luar Islam pun memandang serius permasalahan riba. Sebab hal ini apabila diruntut secara sejarah, riba telah menjadi bahasan di kalangan Yahudi, Yunani, demikian juga Romawi serta kalangan Kristen yang memiliki pandangan tersendiri dari masa kemasa mengenai riba.

Para pakar sejarah ekonomi menyimpulkan kegiatan bisnis dengan sistem bunga telah ada sejak tahun 2500 sebelum Masehi, baik Yunani Kuno, Romawi Kuno. Pada tahun 2000 Sebelum Masehi, di Messopotamia (wilayah Irak sekarang), telah berkembang sistem bunga, sementara itu 500 tahun sebelum Masehi, Temple of Babilan mengenakan bunga sebesar $20 \%$.

Tradisi bunga juga berkembang di tanah Arab sebelum Nabi Muhammad menjadi Rasul. Catatan sejarah menunjukkan bangsa Arab cukup maju dalam perdagangan. Hal ini digambarkan oleh al-Qur'an dalam surah al-Quraisy dan buku-buku sejarah dunia. Bahkan kota Mekkah saat itu pernah menjadi kota perdagangan internasional yang di dalalui tiga jalur perdagangan dunia: Eropa dan Afrika, India dan Cina, serta Syam dan Yaman. Untuk menunjang atas perdagangan yang begitu pesat, mereka membutuhkan fasilitas pembiayaan yang memadai guna mendukung kegiatan produksi. Peminjam modal untuk perdagangan dilakukan dengan sistem bunga. Tegasnya, pinjaman uang saat itu, bukan semata untuk konsumsi, tetapi juga untuk usaha-usaha produksi.

Kaum Yahudi dalam ajaran agamanya pun dilarang untuk mempraktekkan pengambilan bunga. Pandangan agama Yahudi mengenai bunga terdapat dalam kitab perjanjian lama maupun undang-undang Talmud. ${ }^{1}$

Riba menjadi bahan pembicaraan oleh ilmuan baik ilmuan barat Barat maupun ilmuan Timur. ${ }^{2}$ Maka perlu untuk mengkaji riba (bunga) dalam pandangan Sejarah dan Agama.

* Dosen tetap Fakultas Ekonomi dan Bisnis Islam Institut ilmu keislaman Zainul hasan genggong Kraksaan Probolinggo

${ }^{1}$ M. Nur Rianto al-Arif, Dasar-dasar Ekonomi Islam (Solo: PT.Era Adicitra intermedia, 2011), Hal. $97-100$ 


\section{B. Pembahasan}

1. Pengertian Riba

Riba secara bahasa berarti penambahan, pertumbuhan, kenaikan, dan ketinggian. Allah SWT berfirman Q.S al-Hajj [22]: 5

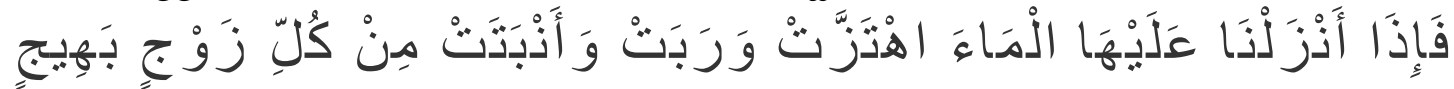

Artinya: Kemudian apabila telah Kami turunkan air di atasnya, niscaya bumi itu subur dan menumbuhkan (Q.S al-Hajj [22]: 5)

Artinya naik dan tinggi. Allah juga berfirman dalam Q.S An-Nahl (16): 92

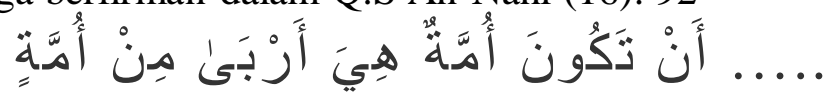

Artinya: Disebabkan adanya satu golongan yang lebih banyak jumlahnya dari golongan yang lain (Q.S An-Nahl (16): 92) ${ }^{3}$

Adapun secara istilah riba berarti pengambilan tambahan dari harta pokok atau mudal secara batil. ${ }^{4}$

Menurut pandangan para ahli tafsir al-Qur'an dan para fuqaha Islam tentang riba yang dikutip oleh Muhammad Sharif Chadhry, diantaranya adalah menurut:

a. Muhammad Asad

Di dalam terminologi al-Qur'an, istilah riba itu menunjukkan tambahan haram apapun, melalui bunga, terhadap sejumlah uang atau barang yang dipinjamkan oleh seseorang atau lembaga kepada orang atau lembaga lain.

b. Syed Abul A'la al-Maududi

Riba digunakan untuk menyebut sejumlah tambahan yang dikenakan oleh kreditur kepada debitur secara tetap pada pokok utang yang ia pinjamkan, yakni bunga.

c. Afzalur Rahman

Afzalur Rahman menjelaskan riba secara rinci berdasarkan pendapat beberapa fuqaha Islam klasik sebagai berikut;

1) Menurut Allamah al-Hasan Taunki, riba berarti kelebihan atau kenaikan, dan didalam kontrak barter (pertukaran barang dengan barang), kelebihan suatu barang diminta untuk ditukar dengan barang yang persis sama, maka itu riba

2) Menurut Shah Waliyullah dari Delhi, unsur riba terletak di dalam utang yang diberikan dengan syarat si pengutang akan membayar lebih banyak atau lebih baik daripada apa yang ia terima dari pemberi utang.

3) Menurut pandangan Imam ar-Razi, adalah kebiasan di masa pra-Islam bahwa mereka meminjamkan uang kepada seseorang selama suatu jangka waktu tertentu lalu menerima darinya suatu suatu jumlah uang tertentu sebagai bunga; jika waktu jatuh tempo tiba, maka pengutang akan diminta melunasi

\footnotetext{
${ }^{2}$ Ismail, Perbankan Syari'ah (Jakarta: Kencana, 2011), Hal. 11

${ }^{3}$ Abdul Aziz Muhammad Azam, Fiqhi Muamalat : Sistem Transaksi dalam Fiqh Islam (Jakarta: Amzah, 2010), Hal.215

${ }^{4}$ Muhammad Syafi'i Antonio, Bank Syariah: Dari Teori ke Praktek (Jakarta: Gema Insani, 2001),Hal. 
utangnya; jika ia tidak dapat membayar, maka ia diberi perpanjangan waktu dan bunganya pun dinaikkan pula. ${ }^{5}$

Dengan demikian, riba meurut istilah ahli fiqh adalah penambahan pada salah satu dari dua ganti yang sejenis tampa ada ganti dari tambahan ini. Namun tidak semua tambahan dianggap dengan riba, karena tambahan terkadang dihasilkan dalam sebuah perdagangan dan tidak ada riba didalamnya hanya saja tambahan yang diistilahkan dengan nama "riba" alQur'an datang menerangkan pengharamnya adalah tambahan yang diambil sebagai ganti dari tempo. ${ }^{6}$

\section{Sejarah Riba}

Riba pada agama-agama langit (samawi) telah dinyatakan haram. Sebagaimana dikutip oleh Muhammad, haramnya riba terdapat dalam Perjanjian Lama dalam Kitab keluaran ayat 25 pasal 22, sebagai berikut:

"Bila kamu menghutangi seseorang diantara warga bangsamu uang maka janganlah kamu berlaku laksana seorang pemberi hutang, jangan kamu meminta keuntungan padanya untuk pemilik uang". Namun orang Yahudi beranggapan bahwa riba itu hanyalah terlarang kalau di lakukan di kalangan sesama Yahudi. Tetapi tidak terlarang dilakukan terhadap non Yahudi. Demikian pula dalam kitab Levcitus (Imamat) pasal 35 ayat 7 dkutip Muhammad, menyatakan:

"janganlah engkau mengambil bunga uang atau riba darinya, malainkan engkau harus takut akan Allahmu, supaya saudaramu bisa hidup diantaramu. Janganlah engkau memberi uangmu kepadanya dengann meminta bunga, juga makananmujanganlah kau berikan dengan meminta riba."

Umat Nasrani dalam hal riba, secara tegas mengharamkan riba bagi semua orang, tampa membedakan kalangan Nasrani maupun non-Nasrani. Tokoh-tokoh Gereja sepakat berpegang kepada ketetapan-ketetapan agama yang ada pada mereka. Yang mengatakan:

"Jika kamu menghutangi kepada orang yang engkau harapkan imbalannya, maka dimana sebenarnya kehormatanmu. Tetapi berbuatlah kebaikan dan berikanlah pinjaman dengan mengharapkan kembalinya. Karena pahala kamu akan sangat banyak."

Ketetapan semacam ini menunjukkan pengharaman riba tegas dalam agama Nasrani. Namun kaum Periba berusaha untuk menghalalkan beberapa keuntungan yang tidak dibenarkan oleh pihak Gereja karena pengaruh ekonomi Yahudi. Akhirnya muncul anggapan dan pendapat, bahwa keuntungan yang diberikan sebagai imbalan administratif dan organisasi dibenarkan. Akhirnya banyak orang yang mengambil fatwa ini sehinga berani menghalalkan apa yang telah diharamkan Allah.

Larangan riba dalam pandangan Islam, telah jelas dinyatakan dalam al-Qur'an (2:278). Larangan tersebut dilatarbelakangi suatu peristiwa atau asbabun-nuzul. Dalam suatu riwayat dikemukakan bahwa turunya ayat (Q.S.[2]:278-279) berkenaan

${ }^{5}$ Muhammad Syarif Chaudhry, Sistem Ekonomi Islam : Prinsip Dasar (Jakarta: Prenadamedia Group, 2012), Hal. 224-228

${ }^{6}$ Abdul Aziz Muhammad Azam, Fiqhi Muamalat : Sistem Transaksi dalam Fiqh Islam. Hal.217 
dengan pengaduan Bani Mungirah kepada Gubernur Mekkah setelah Fathu Makkah, yaitu 'Attab bin As-yad tentang hutang-hutangnya yang ber-riba sebelum ada hukum pengharaman riba, kepada banu 'Amr bin 'Auf dari suku Tsaqif. Bani Mughirah berkata kepada "Attab bin As-yad: "Kami adalah manusia yang paling menderita akibat dihapusnya riba. Kami ditagih membayar riba oleh orang lain, sedang kami tidak mau menerima riba karna mentaati hukum penghapusan riba". Maka berkata Banu "Amr; "Kami minta penyelesaian atau tagihan riba kami". Maka Gubernur 'Attab menulis surat kepada Rasulullah SAW. Yang dijawab oleh Nabi sesuai dengan ayat 278-279: "Hai orang-orang yang beriman, bertaqwalah kepada Allah dan tinggalkan sisa riba (yang belum dipungut) jika kamu orang-orang yang beriman"; "Maka jika kamu tidak mengerjakan (meninggalkan sisa riba), maka ketahuilah bahwa Allah dan Rasul-Nya akan memeragimu. Dan jika kamu bertaubat (dari pengambilan riba), maka bagimu pokok hartamu; kamu tidak menganiaya dan tidak (pula) dianiaya.

Dari peristiwa tersebut, jelas bahwa setelah datangnya hukum yang tidak memperbolehkan praktik riba, baik dalam bentuk besar maupun kecil, maka praktek tersebut harus sudah berakhir. ${ }^{7}$

Kini Seluruh pakar ekononomi Islam di dunia telah ijma' menetapkan keharaman bunga bank. Pada Tahun 1976, 300 ahli dunia bersama para ulama seluruh dunia dalam konfrensi I Ekonomi Islam Internasional, menetapkan keharaman bunga bank dan menetapkan keharusan umat Islam mendukung bank syariah tampa bunga yang sesuai dengan ayat al-Qur'an dan as-Sunnah. Demikian pula ulama-ulama OKI yang terdiri 54 negara. Mereka sepakat mengharamkan bunga bank dan mengharuskan umat Islam mengembangkan dan mengongkretkan konsep bank Islam. ${ }^{8}$

3. Riba dalam pandangan Agama

1. Riba dalam pandangan Kalangan Yahudi

Orang-orang Yahudi dilarang mempraktekkan pengambilan bunga. Pelarangan ini banyak terdapat dalam kitab suci mereka, baik dalam Old Testament (Perjanjian Lama) mapun undang-undang Talmud.

Kitab Exodus (Keluaran) pasal 22 ayat 25 menyatakan:

"Jika engkau meminjamkan uang kepada salah seorang dari ummat-Ku, orang yang miskin diantaramu, maka janganlah engkau berlaku sebagai penagih utang terhadap dia: janganlah engkau bebankan bunga terhadapnya."

Kitab Deuteronomi (Ulangan) pasal 23 ayat 19 menyatakan:

"Janganlah engkau membungakan kepada saudaramu, baik uang maupun bahan makanan, atau apapun yang dapat dibungakan,"

Kitap Levicitus (Imamat) pasal 25 ayat 36-37 menyatakan:

"janganlah engkau mengambil bunga uang atau riba darinya, melainkan engkau harus takut akan allahmu, supaya saudaramu bisa hidup diantaramu. Janganlah

${ }^{7}$ Muhammad, Bank Syariah: Analisis Kekuatan, Peluang, Kelemahan dan Ancaman (Yogyakrta: Ekonisia, 2003), Hal. 24- 27

${ }^{8}$ M. Nur Rianto al-Arif, Dasar-dasar Ekonomi Islam. Hal.101 
engkau memberi uangmu kepadanya dengan meminta bunga, juga makananmu janganlah kauberikan dengan meminta riba." ${ }^{\prime 9}$

2. Riba dalam pandangan masyarakat Romawi dan Yunani

Sejak zaman Dahulu sebelum Islam muncul, praktek riba sudah tidak diperbolehkan. Larangan riba berlangsung umum. Masyarakat Romawi dan Yunani melarang pungutan bunga di wilayahnya. Bunga pada saat itu benar-benar dilarang dengan hukum yang ketat.

Plato dan Aristoteles, ahli filsafat Yunani, mengecam praktik bunga dan mengutuk orang Romawi yang memungut bunga atas pinjaman yang di berikan oleh pemberi pinjaman kepada peminjam.

Ada dua alasan adanya larangan bunga dalam setiap pinjaman, menurut Plato yaitu:

1) Bunga merupakan alat yang digunakan oleh masyarakat golongan kaya untuk merampas masyarakat golongan miskin, sehingga masyarakat golongan miskin akan tetap menderita dengan adanya pembayaran yang melebihi pokok pinjamannya.

2) Bunga dapat menyebabkan perpecahan dan adanya perasaan tidak puas dari masyarakat golongan miskin yang selalu menjadi objek kezaliman.

Aristoteles, menyatakan bahwa uang berfungsi sebagai alat tukar, bukan sebagai alat untuk menghasilkan tambahan berupa bunga. Pengambilan bunga secara tetap tampa memperhatikan hasil usaha pihak yang mendapatkan pinjaman merupakan sesuatu yang tidak adil. Peminjam belum tentu mendapat keuntungan atas hasil usahannya, akan tetapi telah dipastikan harus membayar bunga.

3. Riba dalam Pandangan Kristen

Kitab Perjanjian baru tidak menyebutkan permasalahan ini secara jelas. Akan tetapi, sebagian kalangan Kristiani menganggap bahwa ayat yang terdapat dalam Lukas 6:34-35 sebagai ayat yang mngecam praktik pengambilan bunga. Ayat tersebut menyatakan:

"Dan, jikalau kamu meminjamkan sesuatu kepada orang karena kamu berharap akan menerima sesuatu darinya", apakah jasamu? Orang-orang yang berdosa pun meminjamkan kepada orang yang berdosa supaya mereka menerima kembali sama bnyak. Tetapi kamu, kasihilah musuhmu dan berbuatlah baik kepada mereka dan pinjamkan dengan tidak mengharapkan balasan, maka upahmu akan besar dan kamu akan menjadi anak-anak Tuhan yang Mahatinggi sebab Ia baik terhadap orang-orang yang tidak tau berterima kasih dan terhadap orang-orang yang jahad."

Ketidak tegasan ayat tersebut mengakibatkan munculnya berbagai tanggapan dan tafsiran dari pemuka agama Kristen tentang boleh-tidaknya orang Kristen mempraktikkan pengambilan bunga. Berbagai pandangan di kalangan pemuka Kristen dapat dikelompokkan menjadi tiga periode utama, yaitu pandangan para pendeta awal Kristen (abad I-XII) yang mengharamkan bunga, pandangan para sarjana Kristen (abad XII-XIV) yang berkeinginan agar bunga diperbolehkan, dan

${ }^{9}$ Muhammad Syafii Antonio, Bank Syariah : Dari Teori ke Praktek. Hal. 43 
pandangan para reformis Kristen (abad XIV-tahun 1836) yang menyebabkan agama Kristen menghalalkan bunga.

1) Pandangan para Pendeta Awal Kristen (Abad I-XII)

Pada masa ini, umunya pengambilan bunga dilarang. Mereka merujuk masalah pengambilan bunga kepada Kitab Perjanjian Lama yang juga diimani oleh orang Kristen, diantaranya adalah:

a) St. Basil (329-378), menganggap mereka yang memakan bunga sebagai orang yang tidak berperikemanusiaan. Baginya, mengambil bunga adalah mengambil keuntungan dari orang-orang yang memerlukan.

b) St. Gregory dari Nyassa (335-395), mengutuk praktek bunga karena menurutnya pertolongan melalui pinjaman adalah palsu. Pada awal konrak seperti membantu, tetapi pada saat menagih dan meminta imbalan bunga bertindak sangat kejam.

c) St. John Chrysostom (344-407), berpendapat bahwa larangan yang terdapat dalam Perjanjian Lama yang ditujukan bagi orang-orang Yahudi juga berlaku bagi penganut Perjanjian Baru.

d) St. Ambrose mengecam pemakan bunga sebagai penipu dan pembeli (rentenir)

e) St. Augustine berpendapat bahwa pemberlakuan bunga pada orang miskin lebih kejam dibandingkan dengan perampok yang merampok orang kaya. Karena dua-duanya sam-sama merampok, satu merampok terhadap orang dan kaya dan satunya terhadap orang miskin.

f) St. Anselm dari Centerbury (1033-1109), menganggap bunga sama dengan perampokan.

Larangan praktik bunga juga dikeluarkan oleh gereja dalam bentuk undang-undang (canon), sebagai berikut:

1) Council of Elvira (Spanyol tahun 306) mengeluarkan Canon 20 yang melarang para pekerja gereja mempraktikkan pengambilan bunga. Barang siapa yang melanggar, pangkatnnya akan diturunkan.

2) Coucil of Arles (tahun 314) mengeluarkan Canon 44 yang juga melarang para pekerja gereja mempraktikkan pengambilan bunga.

3) First Council of Nicaea (tahun 325) mengeluarkan Canon 17 yang mengancam akan memecat para pekerja gereja yang mempratikkan bunga.

4) Larangan pemberlakuan bunga untuk umum baru dikeluarkan pada Council of Vienne (tahun 1311) yang menyatakan bahwa barangsiapa menganggap bunga itu adalah sesuatu yang tidak berdosa, ia telah keluar dari Kristen (murni).

2) Pandangan Para Sarjana Kristen (Abad XII-XVI)

Pada masa ini terjadi perkembngan yang sangat pesat di bidang perekonomian dan perdagangan. Pada masa tersebut, uang dan kredit menjadi unsur yang penting dalam masyarakat. Pinjaman untuk memberi mudal kerja kepada para pedagang mulai digulirkan pada awak abad XII. Pasar uang perlahan-perlahan mulai terbentuk. Proses tersebut mendorong terwujudnya suku bunga pasar secara meluas. 
Para sarjana Kristen pada masa itu tidak saja membahas permasalahan bunga dari segi mural semata yang merujuk kepada ayat-ayat Perjanjian Lama maupun Perjanjian Baru, mereka juga mengaitkan dengan aspek-aspek lain. Di antaranya, menyangkut jenis dan makna keadilan, bentuk-bentuk keuntungan, niat dan perbuatan manusia, serta perbedaan antara dosa individu dan kelompok. Dari hasil bahasan mereka untuk tujuan memperhalus dan melegitimasi hukum, bunga dibedakan menjadi interest dan usury. Menurut mereka, interest adalah bunga yang diperbolehkan, sedangkan usury adalah bunga yang berlebihan. Para tokoh para tokoh sarjana Kristen yang memberikan kontribusi pendapat yang sangat besar sehubungan dengan bunga adalah Robert of Courcon (1180-1218), William of Auxxerre (1160-1220), St. Raymond of Pennaforte (1180-1278), St. Bonaventure (1221-1274), dan St. Thomas Aquinas (1225-1274).

Hasil bahasan para sarjana Kristen pada periode tersebut sehubungan dengan bunga adalah sebagai berikut:

1. Niat atau perbuatan untuk mendapatkan keuntungan dengan memberikan pinjaman adalah suatu dosa yang bertentangan dengan konsep keadilan.

2. Mengambil bunga dari pinjaman diperbolehkan, namun haram atau tidaknya tergantung pada niat si pemberi utang.

3) Pandangan Para Reformis Kristen (Abad XVI-1836)

Pandangan para reformis telah mengubah dan membentuk pandangan baru mengenai bunga. Para reformis itu antara lain: John Calvin (1509-1564), Charles du Moulin (1500-1566), Chaude Saumaise (1588-1653), Martin Luther (1483-1546), Meanchthon (1497-1560), dan Zwingli (1484-1531).

Beberapa pendapat Calvin sehubungan dengan bunga antara lain:

1) Dosa apabila bunga memberatkan

2) Uang dapat membiak (kontra dengan Aristoteles),

3) Tidak menjadikan pengambil bunga sebagai profesi,

4) Jangan mengambil dari orang miskin.

$\mathrm{Du}$ Moulin mendesak agar pengambilan bunga yang sederhana diperbolehkan asalkan bunga tersebut digunakan untuk kepentingan produktif. Saumise, seorang pengikut Calvin, membenarkan semua pengambilan bunga, meskipun ia berasal dari orang miskin. Menurutnya menjual uang dengan uang adalah seperti perdagangan biasa. Oleh kerena itu, tidak ada alasan untuk melarang orang yang akan menggunakan uangnya untuk membuat uang. ${ }^{10}$

4. Riba dalam Pandangan Nasroni

Kaum gereja pada abad pertengahan, melarang adanya bunga. Dalam kitab Injil disampaikan bahwa bunga itu jelas dilarang. "Beri pinjaman, dan jangan berharap sesuatu yang lain." Larangan bunga dari pelopor gereja terus berlaku hingga Abad Pertengahan, yang berahir pada abad ke-13.

Pandangan para pendeta Kristen pada Abad Pertengahan secara garis besar dapat disimpulkan sebagai berikut:

${ }^{10}$ Muhammad Syafii Antonio, Bank Syariah : Dari Teori ke Praktek. Hal. 45-48 
1) Bunga merupakan suatu tambahan atas pinjaman yang diberikan, yang telah diperjanjikan pada saat awal.

2) Pengambilan bunga merupakan suatu dosa yang di larang

3) Niat seorang pemberi pinjaman untuk mendapatkan tambahan atas pinjaman yang diberikan adalah dosa.

4) Bunga yang dibebankan kepada peminjam bukan menjadi hak pemberi pinjaman, oleh karena itu harus dikembalikan kepada pihak peminjam.

5) Perbedaan harga antara penjualan barang secara tunai dan penjualan barang dengan pembayaran ditunda merupakan praktik bunga yang terselubung, sehingga dilarang. ${ }^{11}$

5. Riba dalam pandangan Islam

Riba dalam al-Qur'an diartikan sebagai setiap penambahan yang diambil tampa adanya satu transaksi pengganti atau penyeimbang yang dibenarkan oleh syari'ah. Yang dimksud sebagai transaksi pengganti atau penyeimbang, yaitu transaksi bisnis komersial yang melegitimasi adanya penambahan secara adil, seperti melalui transaksi jual beli, sewa-menyewa, atau bagi hasil.

Islam tidak mengenal prinsip time velue of money yang berbasis pada bunga layaknya transaksi ekonomi konvensional, karena dalam Islam tidak mungkin ada keuntungan tampa ada resiko dan atau mendapatkan pendapatan tampa biaya. Islam lebih menekankan pada prinsip prinsip nilai ekonommi atas waktu (ekonomi value of time). Artinya bahwa waktu memiliki nilai ekonomi sepanjang digunakan untuk kegiatan produktif. Lebih lanjut ditegaskan bahwa Islam melarang riba dalam segala bentuk dan manifestasinya. ${ }^{12}$

Islam dengan tegas melarang praktik riba. Hal ini terdapat dalam al-Qur'an dan as-Sunah. Al-Qur'an menyatakan haram terhadap riba bagi kalangan masyarakat muslim. Allah SWT. Telah mewahyukan adanya larangan riba secara bertahap, sehingga tidak mengganggu kehidupan ekonomi masayarakat pada waktu itu. ${ }^{13}$

1) Riba dalam Al-Qur'an

Di masa awal Muncunya Islam, bunga telah ada dalam masyarakat Arab baik dalam transaksi pinjaman uang maupun transaksi barter komoditas. Oleh kerana itu riba mengakar dalam kehidupan ekonomi masyarakat, maka dalam melarang riba pun al-Qur'an diwahyukan secara berangsur-angsur. Berikut adalah beberapa ayat al-Qur'an yang berkaitan dengan riba (bunga)

a) Q.S. ar-Rum [30]: 39

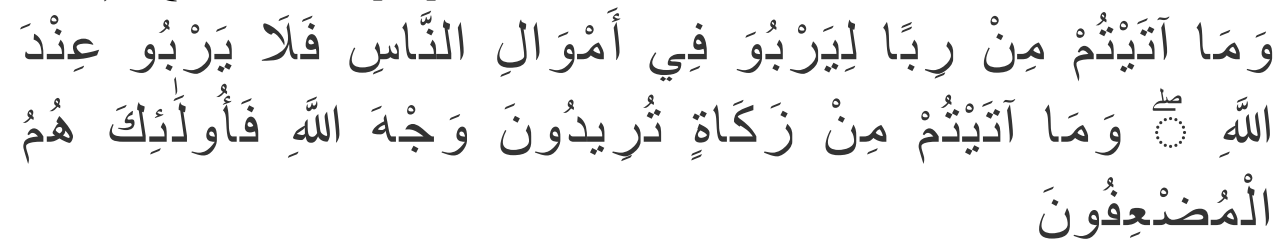

${ }^{11}$ Ismail, Perbankan Syariah (Jakarta: Kencana, 2011), Hal. 15-17

12 Abdul Ghofur Anshori, Perbankan Syariah Di Indonesia (Yogyakrta: Gajah Mada University Press, 2009), Hal. 13-12

${ }^{13}$ Ismail. Perbankan Syariah. Hal. 17 
Artinya: dan sesuatu Riba (tambahan) yang kamu berikan agar Dia bertambah pada harta manusia, Maka Riba itu tidak menambah pada sisi Allah. dan apa yang kamu berikan berupa zakat yang kamu maksudkan untuk mencapai keridhaan Allah, Maka (yang berbuat demikian) Itulah orang-orang yang melipat gandakan (pahalanya). (Q. S. ar-Rum [30]: 39)

b) Q.S. an-Nisa' [4]: 161

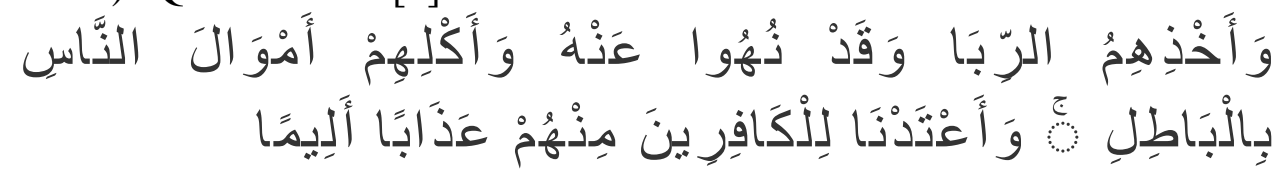

Artinya: dan disebabkan mereka memakan riba, Padahal Sesungguhnya mereka telah dilarang daripadanya, dan karena mereka memakan harta benda orang dengan jalan yang batil. Kami telah menyediakan untuk orang-orang yang kafir di antara mereka itu siksa yang pedih. (Q.S. anNisa' [4]: 161)

c) Q.S. al-Imran [3]: 130

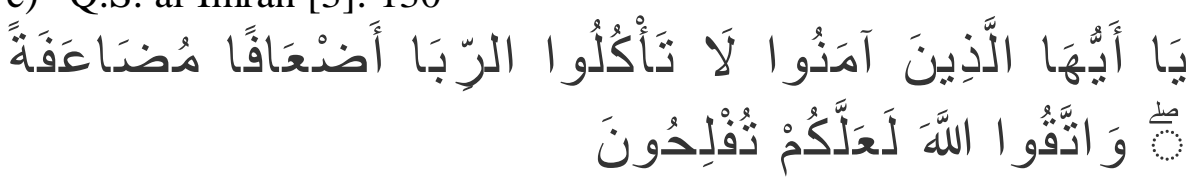

Artinya: Hai orang-orang yang beriman, janganlah kamu memakan Riba dengan berlipat ganda dan bertakwalah kamu kepada Allah supaya kamu mendapat keberuntungan. (Q. S. al-Imran [3]: 130)

d) Q. S. al-Baqarah [2]: 275-276

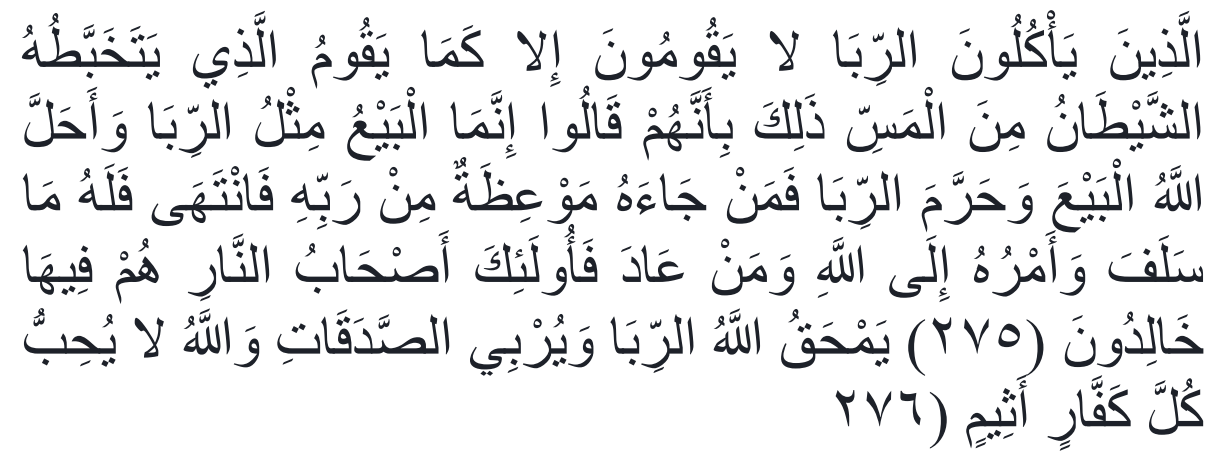

Artinya: Orang-orang yang Makan (mengambil) riba tidak dapat berdiri melainkan seperti berdirinya orang yang kemasukan syaitan lantaran (tekanan) penyakit gila Keadaan mereka yang demikian itu, adalah disebabkan mereka berkata (berpendapat), Sesungguhnya jual beli itu sama dengan riba, Padahal Allah telah menghalalkan jual beli dan mengharamkan riba. orang-orang yang telah sampai kepadanya larangan dari Tuhannya, lalu terus berhenti (dari mengambil riba), Maka baginya apa yang telah diambilnya dahulu (sebelum datang larangan); dan urusannya (terserah) kepada Allah. orang yang kembali (mengambil riba), Maka orang itu adalah penghuni-penghuni neraka; mereka kekal di dalamnya. 
Allah memusnahkan Riba dan menyuburkan sedekah. Dan Allah tidak menyukai Setiap orang yang tetap dalam kekafiran, dan selalu berbuat dosa.

e) Q. S. al-Baqarah [2]: 278-279

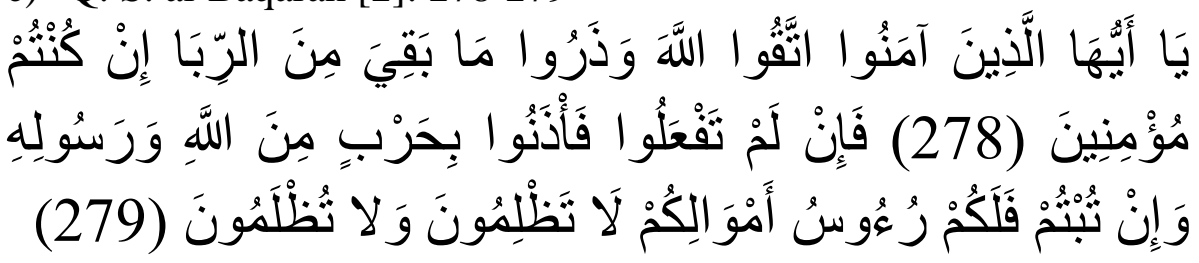

Artinya: Hai orang-orang yang beriman, bertakwalah kepada Allah dan tinggalkan sisa Riba (yang belum dipungut) jika kamu orang-orang yang beriman. Maka jika kamu tidak mengerjakan (meninggalkan sisa riba), Maka ketahuilah, bahwa Allah dan Rasul-Nya akan memerangimu. dan jika kamu bertaubat (dari pengambilan riba), Maka bagimu pokok hartamu; kamu tidak Menganiaya dan tidak (pula) dianiaya. (Q. S. alBaqarah [2]: 278-279)

Jika diurutkan waktu diturunkannya, ayat tersebut secara berangsurangsur melarang bunga. Ayat yang pertamadalam al-Qur'an (ar-Rum [30]: 39) diturunkan mengenai bunga yang dibandingkan denga zakat. Di situ dinyatakan bahwa bunga tidak menambah harta manusia, malah sebaliknya, yaitu mengurangi, sementara zakat meningkatnya secara berlipat-lipat.

Dalam ayat yang turun berikut (al-Imran [3]: 130), kaum Mukminin diberitahu agar tidak makan bunga-berbunga yang berlipat hingga dua atau bahkan empat kali jumlah asal pinjaman. Dalam ayat berikutnya (Q.S. an-Nisa' [4]: 161), kaum Muslimin diingatkan untuk mematuhi perintah al-Qur'an menganai pelangan bunga agar mereka tidak usah merasakan derita kaum Yahudi yang melanggar larangan bunga dan akan menerima siksa yang pedih. Ahirnya turunlah ayat wahyu terahir (Q.S. alBaqarah [2]: 275,276, 278 dan 279) yang melarang bunga. Ayat-ayat ini membedakan antara perdagangan (ba'i) dan bunga (riba). Ayat ini mengutuk bunga berikut pemakannya dan memuji keberkahan sedekah. Ayat tersebut secara mutlak melarang pemungutan bunga dan memerintahkan kaum Mukminin untuk menghentikannya serta menerima pengembalian hanya modal pokoknya saja. ${ }^{14}$

2) Riba dalam Hadis

Muslim:

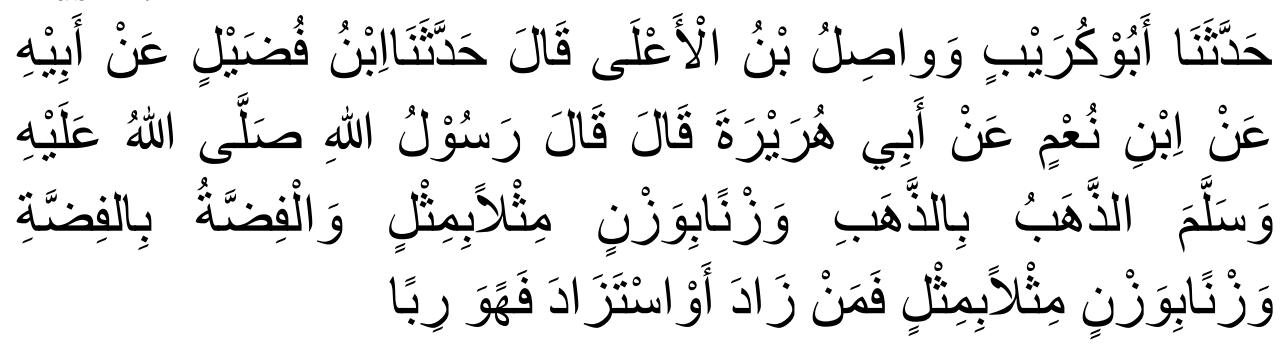

${ }^{14}$ Muhammad Syarif Chaudhary. Sistem Ekonomi Islam : Prinsip Dasar. Hal. 215-217 
Rasulullah Saw. bersabda: "Emas dengan emas sama timbangan dan ukurannya, perak dengan perak sama timbangan dan ukurannya. Barang siapa meminta lebih maka teramsuk riba."

(Matan lain: Ahmad 13744)

Dari hadis tersebut dapat dipahami bahwa apabila tukar menukar emas atau perak maka harus sama ukuran dan timbangannya, jika tidak sama maka teramasuk riba. Dari sini dapat dipahami bahwa riba adalah ziyadah atau tambahan. Akan tetapi tidak semua tambahan adalah riba.

a) Ancaman bagi Pelaku Riba

Muslim

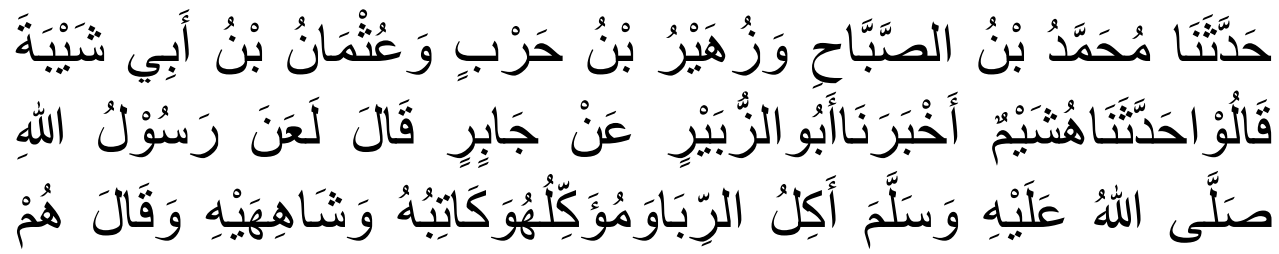

سَوَ اعُّ

Rasulullah melaknat pemakan riba, pemberinya, penulisnya, kedua saksinya, mereka semua sama.

(Mata lain: Ahmad: 13744)

Riba diharamkan baik dalam al-Qur'an maupun hadis. Berikut ini beberapa hadis hadis yang melarang dan mengecam praktik riba dengan kata-kata yang tegas dan jelas.

Ahmad:

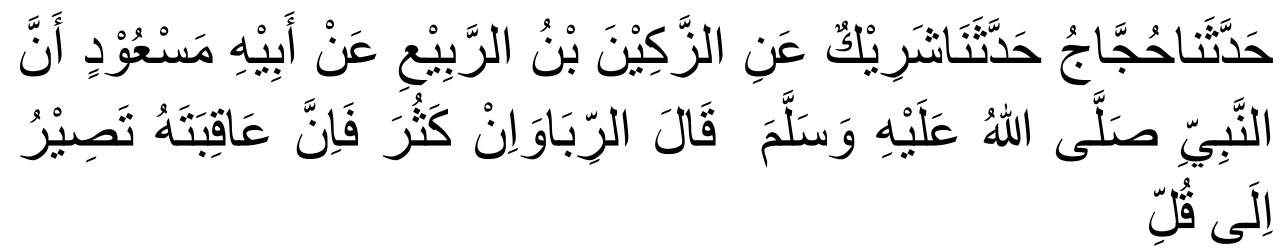

Nabi Saw. bersabad: "Riba itu sekalipun dapat menyebabkan bertambah banyak, tetapi akibantnya akan berkurang.

(Matan lain: Ibnu Majah 2270)

Hadis ini merupakan ancaman bagi orang-orang yang melakukan praktik riba, bahwa riba mmang dapat mendatangkan keuntungan besar bagi pelakunya, tatapi suatu saat tidak akan mendapatkan berkah dari Allah, sehingga pada akhirnya akan berkurang.

b) Jenis-jenis riba

Secara garis besar riba dikelompokkan menjadi dua, yaitu riba utang piutang dan riba jual beli. Kelompok pertama terbagi menjadi riba qard dan jahiliyah, sedang kelompok kedua ada dua macam, yaitu riba fadl dan nasi'ah

a.) Riba Qard: suatu manfaat yang disyaratkan terhadap yang berhutang (mugtaridh)

b.) Riba jahiliyah: Utang dibayar lebih dari pokoknya karena sipeminjam tidak dapat membayar pada waktu yang ditentukan. 
Muslim:

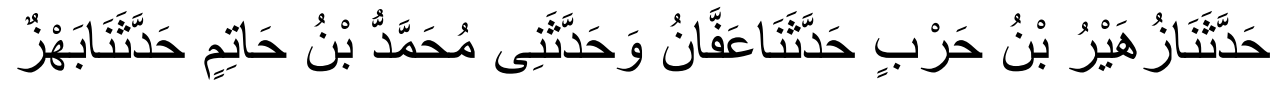

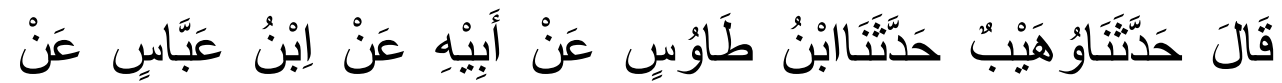

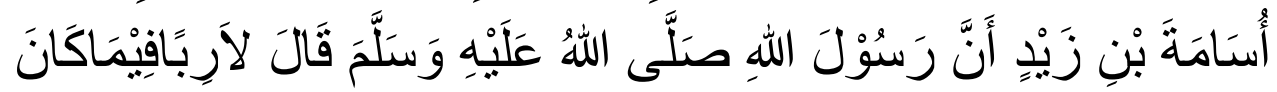

بَدَاِِيَِدِ

Rasulullah Saw. bersabda: "Tidak ada riba dalam hal tunai/serah terima."

(Matan lain: Bukhari 2030, 2032, Nasa'i 4504-4505, Ibnu Majah 2248, Ahmad 20749, 20762, 20767, 20779, 20796, 20814, 20816, Darimi, 2467)

c.) Riba fadl: pertukaran antra barang sejenis dengan kadar atau takaran yang berbeda.

Bukhari:

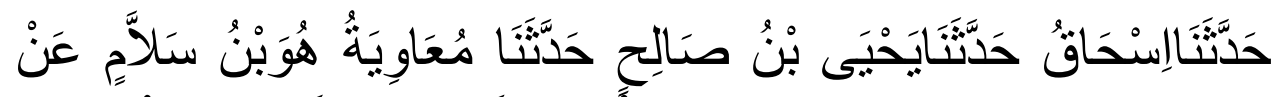

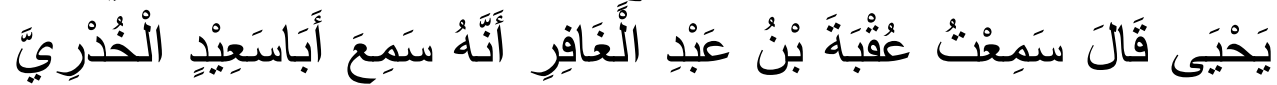

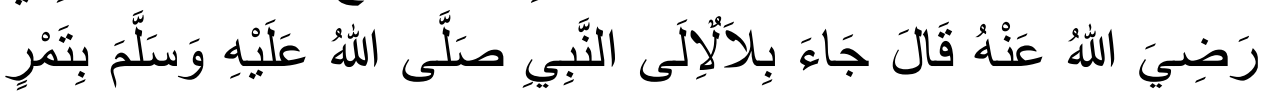

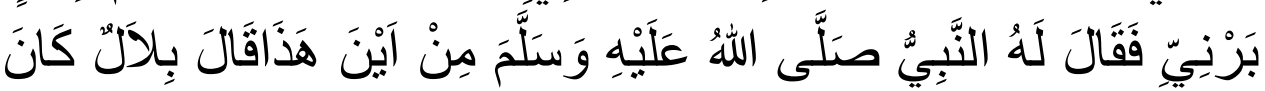

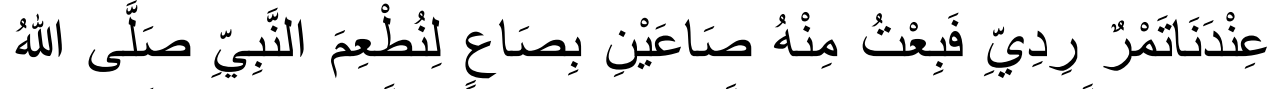

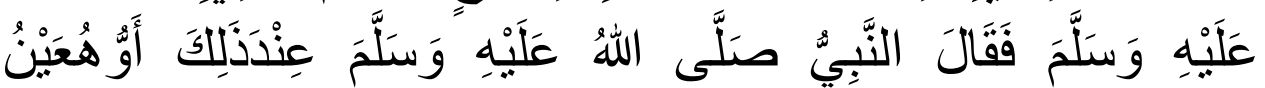

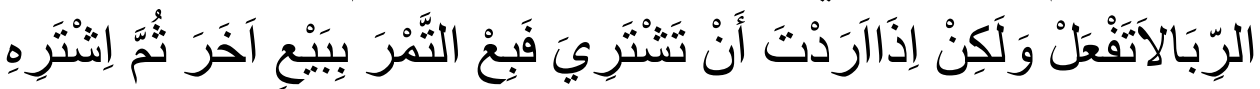

Abi Sa'id al-Khudari berkata: "Bilal datang pada Nabi dengan membawa kurma barni. Nabi Saw. bertanya, dari mana ini? Bilal menjawab, hasil tukar kurma yang rendah mutunya dengan kurma barni, sayar menukar 2 so' kurma rendah dengan 1 so' kurma barni untuk memberi Nabi untuk dimakan. "Beliau bersabda: "jangan, inilah hakikat riba, jangan lakukan. Kalau kamu ingin maka juallah lebih dulu kurmamu kemudian beli jenis kurma lain."

(Matan lain: Muslim 2985, 2986, 2988, 2989, Nasa'I 4477, 4478, 2981, Ahmad 10986, 11031, 11102, 11129, 11167, 11213)

d.) Riba nasi'ah: Penanggunan penyerahan atau penerimaan jenis barang ribawi yang di pertukarkan dengan jenis barang ribawi lainnya. Riba ini muncul karena adanya perbedaan, perubahan atau tambahan antara yang diserahkan saat ini dan yang diserahkan kemudian.

An-Nasa'i:

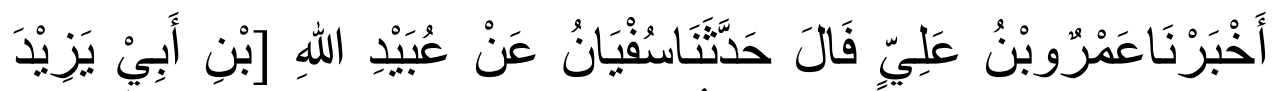

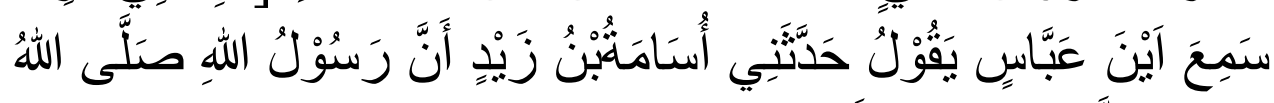

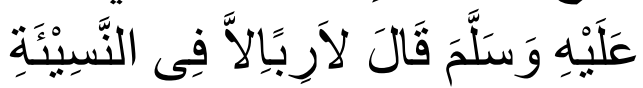

Nabi Saw. bersabda: "Tidak ada riba kecuali nasi'ah." 
(Matan lain: Bukhari 2033, 2990-2993, Ibnu Majah, 2248, Ahmad 20748, 20762, 20767, 20779, 20796, 20814, 20816)

Hadis tersebut bukan berarti hanya riba nasi'ah yang diharamkan, semua riba haram. Asbabul wurudnya adalah Nabi ditanya tentang pertukaran antara gandum dan syair, emas dan perak dengan pembayaran diakhirkan. Hadis ini lebih tepat jika dipahami, bahwa riba nasi'ah adalah riba yang terberat dibandingkan dengan riba lainnya. ${ }^{15}$

4. Dampak riba (bunga) dilarang

Tentang alasan riba (bunga) dilarang, terdapat beberapa pandangan yang saling berbeda. Namun mereka sepakat mengenai satu hal, yakni pelarangan tersebut karena alasan adanya adnya bahaya moral, sosial, dan ekonomi di dalam bunga.

a. Riba atau bunga menanamkan rasa kikir, mementingkan diri sendiri, tak berperasaan, tak peduli dan kejam. Bunga menghancurkan semanat simpati, saling tolong-menolong dan kerja sama, serta mempengaruhi persaudaraan dan persatuan didalam masyarakat.

b. Bunga mengembangbiakkan kemalasan dan menimbulkan pendapatan tampa bekerja.

c. Bunga juga menyebabkan timbulnya kejahatan ekonomi. Ia mendorong orang melakukan penimbunan (hoarding) uang, sehinggga mempengaruhi perederannya di antara sebagian besar masayarakat. Ia juga menyebabkan timbulnya monopoli, kartel serta konsentrasi kekayaan ditangan sedikit orang. Dengan demikian, distribusi kekayaan di dalam masyarakat tidak merata dan celah antara si kaya dan si miskin pun melebar.

d. Investasi modal terhalang dari perusahaan-perusahaan yang tidak mampu menghasilkan laba yang sama atau yang lebih tinggi dari suku bunga yang sedang berjalan, sekalipun proyek yang ditangani oleh perusahaan itu sangat penting bagi neagara dan bangsa.

e. Bunga yang dipungut pada utang internasional malah lebih buruk lagi karena memperparah DSR (debt-service ratio) negara-nagara debitur. Bunga itu tidak hanya menghalangi pembangunan negara-negar miskin, melainkan juga menimbulkan tansfer sumber daya dari negara miskin ke nagara kaya. ${ }^{16}$

\section{Kesimpulan}

Riba dalam agama samawi telah dinyatakan haram, keharamnya riba tersebut terdapat dalam Perjanjian Lama dalam Kitab keluaran ayat 25 pasal 22, begitupun Umat Nasrani dalam hal riba, secara tegas mengharamkan riba bagi semua orang, tampa membedakan kalangan Nasrani maupun non-Nasrani. dalam pandangan Islam pun telah jelas dinyatakan haram dalam al-Qur'an (2:278). Larangan tersebut dilatarbelakangi suatu peristiwa atau asbabun-nuzul. Dari peristiwa tersebut, jelas bahwa setelah datangnya hukum yang tidak memperbolehkan praktik riba, baik dalam bentuk besar maupun kecil

\footnotetext{
${ }^{15}$ Lifi Nurdiana, Hadis-hsdis Ekonomi, (Malang:UIN-Maliki Press,2012), Hal.129-135

${ }^{16}$ Muhammad Syarif Chaudhary. Sistem Ekonomi Islam : Prinsip Dasar. Hal.235-236
} 
Riba dalam pandangan agama orang-orang Yahudi melarang mempraktekkan pengambilan bunga. Pelarangan ini banyak terdapat dalam kitab suci mereka, baik dalam Old Testament (Perjanjian Lama) mapun undang-undang Talmud. Dalam masyarakat Romawi dan Yunani melarang pungutan bunga di wilayahnya. Bunga pada saat itu benar-benar dilarang dengan hukum yang ketat. dikalangan Kristiani menganggap bahwa ayat yang terdapat dalam Lukas 6:34-35 sebagai ayat yang mngecam praktik pengambilan bunga. Kaum gereja pada abad pertengahan, melarang adanya bunga. Dalam kitab Injil disampaikan bahwa bunga itu jelas dilarang. "Beri pinjaman, dan jangan berharap sesuatu yang lain." Larangan bunga dari pelopor gereja terus berlaku hingga Abad Pertengahan, yang berahir pada abad ke13. Dalam agama Islam pun dengan tegas melarang praktik riba. Hal ini terdapat dalam alQur'an dan as-Sunah. Al-Qur'an menyatakan haram terhadap riba bagi kalangan masyarakat muslim. Allah SWT. Telah mewahyukan adanya larangan riba secara bertahap, sehingga tidak mengganggu kehidupan ekonomi masayarakat pada waktu itu. 


\section{Daftar Pustaka}

Aziz, Abdul, Muhammad Azam, 2010. Fiqhi Muamalat : Sistem Transaksi dalam Fiqh Islam (Jakarta: Amzah)

Ghofur, Abdul, Anshori, 2009. Perbankan Syariah Di Indonesia (Yogyakrta: Gajah Mada University Press.)

Muhammad, 2003. Bank Syariah: Analisis Kekuatan, Peluang, Kelemahan dan Ancaman (Yogyakrta: Ekonisia)

Nurdiana, Lifi, 2012. Hadis-hsdis Ekonom: Malang:UIN-Maliki Press.

Rianto, M. Nur, al-Arif, 2011. Dasar-dasar Ekonomi Islam (Solo: PT.Era Adicitra intermedia)

Ismail, 2011. Perbankan Syari'ah: (Jakarta: Kencana)

Syafi'i, Muhammad, Antonio, 2000. Bank Syariah: Dari Teori ke Prkatek (Jakarta: Gema Insani)

Syarif, Muhammad, Chaudhry, 2012. Sistem Ekonomi Islam : Prinsip Dasar (Jakarta: Prenadamedia Group) 